\title{
Tourism modelling for the space coast
}

\author{
C. Cook $^{1}$, F. DeCaro ${ }^{2} \&$ N. DeCaro ${ }^{1}$ \\ ${ }^{I}$ Nathan M. Bisk College of Business, \\ Florida Institute of Technology, USA \\ ${ }^{2}$ Greenleaf University, USA
}

\begin{abstract}
Modelling for tourism must start with a strong foundation of strategic planning and understanding of the specific areas of tourism life cycles, which will result in an increase of local revenues, tax income, employment, and conservation of local ecosystems. This is a descriptive research design with the objective to develop a tourism flow model that takes information from tourism data-sets, business surveys, and state and local projects and builds a picture of current and future tourism flows in Brevard County (the Space Coast), Florida. This tourism model will serve as a tool for gauging tourism on the Space Coast. The question that must be addressed is that the model must answer the problems of how strategic planning initiatives will fill the void between anticipated workplace downsizing and the subsequent reduction of tourist activity, with the approaching retirement of the National Aeronautics and Space Administration's (NASA) shuttle fleet. It is forecasted that more than a quarter of a million workers may suffer job losses in hospitality, manufacturing, business services, and aerospace along the Space Coast. This tourism flow model would be an analysis tool for Space Coast tourism stakeholders to understand the impact of tourism growth and the development of sustainable and unsustainable industries for the area. Next, the model will attempt to identify areas from both private and public investments necessary for high impact revenue results for the Space Coast, while preserving the historic local environment and culture. Lastly, the model will be used to facilitate decisionmaking and planning for government planning boards, and the various tourism committees and councils as to where to invest and adopt pro-active polices for resource allocation in the county. The conclusion of the study will be a practical tourism flow model, which can be used to provide for rigorous discussion.
\end{abstract}

Keywords: tourism, strategic planning, tourism life cycles, ecosystems, sustainable and unsustainable industries, brevard county, space coast, NASA, tourism flow model. 


\section{Introduction}

The rational for this study was to examine the Brevard County Space Coast tourism industry. Findings indicate that the current strategy employed by the local government agencies are failing to take into account the changing times that are pressing against the county with economic hardships and the possible fallouts from the end of the shuttle program. Several hardships to overcome will come in the form of: local layoffs and unemployment; the country's population shrinking, which means fewer customers for local businesses; a decrease in charitable giving; lower tax rolls leading to cuts in public services; the possible closing of the National Aeronautics and Space Administration (NASA); the failure to attract a large segment of the tourism population visiting central Florida's major attractions such as Disney World and Universal Studios; and the lack of an all-encompassing plan which would bring together a number of small businesses that individually make up the tourism attractions in Brevard County. Currently, there are areas of interest to be built upon which include dining, shopping, area attractions along the beachside and coastlines, and historic sites located in Cocoa, Melbourne, and Titusville.

\section{Tourism}

Tourism activity has experienced worldwide growth in recent decades with results in employment, increase of local revenues, tax income, and impacts on local ecosystems. The tourist industry involves close interactions between tourist flows, local authorities, and natural resources. Tourism is an economic reality and plays an important role in the governance structure of many countries. This has contributed to the importance of sustainable and unsustainable development - environmentally, socially, and economically [1]. Tourists have different propensities to visit certain places and travel patterns are influenced by where they reside. The determinant of tourism can be by purpose, destination, and by season - tourists have higher propensity to visit some areas during the spring/summer or during the autumn/winter periods [2].

In the United States, the responsibility for tourism development is shared by public officials at federal, state, and local levels, along with domestic and foreign commercial agents and tourists; all have impacts on the tourism performance of a region. Public officials play a crucial role in shaping and performance of tourism. According to Dinica [1], public officials oversee a large number of policy domains that influence how tourism develops, such as spatial planning, infrastructural development, fiscal policies, transport policies, labour policies, and water management. Public officials also hold the main responsibility for projected tourism growth for sustainable and unsustainable development with policies that influence conservation, such as nature and environmental protection, cultural heritage, waste management, and energy efficiency $[1,3]$. Governance for tourism requires relevant policy making decisions associated with strategic plans. 
Tourism has many different components and given the complexities of tourism, there is a need for principles that can be coordinated for sustainable and unsustainable development. To help forecast demand for tourism on the Space Coast, a model, with a focus on tourism life-cycle and data sets, may answer questions on policy for tourism friendly governance. According to May et al [3], methods have been proposed to extract requirements from policies and regulations using formal models. Giorgini et al [4] described a framework that enabled modelling of actors and goals and their relationships. Thus, a model is an accepted tool for providing public agencies with accessible information to make important tourism related decisions. Using tourism data sets, a model can provide an understanding of tourism life cycle and activity. Tourism life cycle represents succession of phases in a long period of time and life cycle modelling flows are concerned with economic production by the phases. Lastly, understanding the impact of tourism growth will facilitate informed decisionmaking on where to invest and where to adopt pro-active policy, planning, and resource allocation practices for the Space Coast. This will ensure that future growth in tourism results in optimum outcomes for sustainable and unsustainable development in the county $[1,5]$.

\section{Models and modelling flows}

Leedy and Ormond [7] defined research as the systematic process of collecting and interpretation of information or data to resolve the problem that initiated the research. The general tools of research for models and modelling flows are computers and their software, techniques of measurement, statistics and language [6]. According to Arthur [6], technology is a science activity of known concepts and methods to given problems. Involved are design projects to fulfil a set of purposes - this means matching a purpose with a concept of structure that will meet it, and put together a combinations of components that will bring the structure to reality [6]. Al-Fedaghi [8] stated information processing models have evolved since 1949 and methods have been proposed to extract requirements from policies and regulations using formal models [3]. Giorgini et al [4] described a framework that enabled modelling actors and goals and their relationships; thus, modelling can be designed as an instrument based on information factors deemed to be important for tourism decisions and an analytical framework to understand Space Coast tourism. A model represents a real world situation and is employed to aid decision makers with preferred solutions to problems through the evaluation of alternatives [9]. Models can vary from basic language expressions to complex computer programs. The type of model and modelling flow required are a function of the quantity of variables, the number of alternatives, and the overall complexity of operation $[6,9]$. When modelling flows are applied in systematic ways, they are effective indicators for analyzing and reasoning, understanding and managing information, and creating new ideas. Modelling flows help to organize information by defining, comparing, sequencing, or finding causes and effects $[6,9]$. Defining may be presented with a single bubble, cluster, affinity diagram, concept map, model 
map, or target map. Comparing may be presented with a decision grid, double bubble, or matrix. Sequencing may be presented with a cycle, flow chart, or flow bubble. Lastly, finding causes and effects may be presented with a fishbone, flowscape, or input-output [9].

\section{Tourism models}

Modelling is a tool utilized in the flow of decision making: decision makers have the ability to analyze the problems, identify the best techniques that can be used to resolve individual segments of the defined problem, and eventually select or develop a model flow that will properly employ the techniques for problem resolution [9]. Thus, the tourism flow model presents a tool for providing past, present and future estimates of tourism on the Space Coast. This model will contribute towards strategic planning initiatives for the purpose of filling the void between anticipated NASA's workplace downsizing and the reduction of tourist activity [9]. A tourism model presents data collected from the tourism life-cycle and data sets. Tourists make decisions for travel by where do they want or need to go and how to get there? The answers to the question are heavily influenced by where the tourist comes from and what season they travel. The model presents flows that describe processes to define spatial layers, lifecycle and data set sources, and how to manage data of sample sizes involving traveller types, traveller origins, year and season, and transport modes $[1,2,8]$. The origin-destination analysis is segmented by mode of transport - what mode of transport tourist use for travel destinations. The modelling completes the network flow analysis by converting travel demand to estimates of transport usage. In addition to travel decision of where to go and how to get there, the model addresses what to do when the tourist reach their destination $[1,2,8]$. The activity parameters include visits, visitor nights, expenditure, accommodation type, transport type, activities undertaken, age group, and travel style. Lastly, the tourist flow perspective is one most important decision because it is the catalyst for many subsequent (downstream) tourism activities $[1,2,8]$. Tourism models presented by Alvares and Lourenco [5] explained the tourism planning and development process. Thus, the use of a model is seen as a tool for analysis of tourism activities. To present an understanding of modelling requirements as they pertain to the field of tourism, there is a need to identify typical problem applications that may occur in the modelling flow. Tourism flow applications fall into the following categories: conceptual flow design, planning, and development; evaluation of the modelling flow configuration with determination of specific tourism resource requirements; and modelling flow assessment with determination of tourism support effectiveness for the Space Coast [9].

Tourism modelling begins with conceptual design, planning, and development for evaluating and comparing alternative concepts, mission scenarios, utilization profiles, performance factors, and support policies [5, 9]. Modelling flow requirements are being defined, specific marketing applications are being evaluated, technical designs are being established, and functional 
allocations are being accomplished. Flow designers have to rely on tourism lifecycle and data sets for analytical techniques such as simulations, dynamic marketing, forecasting, and networking to structure the modelling flow. Depth of design and life-cycle data sets analyses continue as progress from conceptual design to development is accomplished $[5,9]$. As the modelling flow progresses, there is a requirement to evaluate configurations. A comprehensive analysis is accomplished for determining specific tourism resource requirements in personnel, facilities, and technical and supportability data [5, 9]. A formal design review is necessary to evaluate various alternative methods for supporting the Space Coast model. Modelling flow requirements may include the utilization of tourism life-cycles and data sets to develop recording, processing, storing, and the reporting of technical and supportability analysis data. In this stage, the modelling flow may become complex in both design and operation [5, 9].

\section{Effectiveness of tourism modelling}

To ensure tourism satisfaction, it is essential that the modelling flow be evaluated in terms of overall effectiveness and efficiency of operation. It is appropriate to determine the effectiveness with modelling requirements that include utilization of computerized programs for the purpose of data collection, analysis, process, storage, and reporting $[5,9]$. These requirements should be compatible with the supportability analysis data processing requirements and the continuous acquisition from the tourism life-cycle and data sets. During the ongoing assessment process, if areas of deficiency are noted, recommendations for improvement can be initiated with proposed changes. Proposed changes should be evaluated in terms of impact on cost, reliability and maintainability characteristics $[5,9]$. After identifying different categories of tourism problems it is important that proper tools be selected for anticipation of modelling flow selections. Many interactions will occur between reliability, maintainability, performance, efficiency, effectiveness, and supportability: a variation in any one will affect the others to varying degrees [7, 9]. However, the model selected must represent the conditions in a realistic manner and allow for an overall productive analysis. Different alternatives are available for evaluation. The model selected must be capable of providing an assessment of each alternative with the objective of reducing risk [7,9]. It also must be comprehensive in structure, but with design flexible such that varying depths of analysis can be accomplished. In addition, the model must allow for easy incorporation of changes without destroying its overall characteristics [7, 9]. In accomplishing a tourism analysis effort, it is necessary that the analyst be able to evaluate the model as an entity, evaluate various segments of the flow on an individual basis along with the optimize element design, and project the results of the segment analysis in the context of the modelling flow system as a whole [7, 9]. In other words, the model should be designed to enable evaluation in its entirety, while allowing for the evaluation of individual segments of the flow and appropriate tourism planning can occur $[7,9]$. 


\section{Background on space coast}

A greater emphasis can be placed on Brevard County Space Coast attractions such as: the Astronaut Memorial Planetarium and Observatory, Brevard Zoo, Brevard Symphony Orchestra, Cocoa Village Art and Craft Show, Canaveral National Seashore and Merritt Island National Wildlife Refuge, Cocoa Beach Pier, Florida Institute of Technology Botanical Gardens, Historical Downtown Melbourne, Kennedy Space Center Visitor Complex, Astronaut Hall of Fame Museum, U.S. Space Walk of Fame, Manatee Sanctuary Park, Space Coast Birding and Wildlife Festival, Annual Melbourne Art Show, Port Canaveral, Ron Jon's Surf Shop, Turkey Creek Sanctuary, and the Space Coast Stadium Sport Arena, coupled with exquisite beaches, that need to be targeted as potential tourism attractions. It is not enough to merely draw tourists with beaches, as this abounds along the entire coastline of the state of Florida. Consequently, what is needed is an emphasis on opportunities for which Orlando and neighbouring counties may not have to offer, while changing the present vision with the goal of creating the excitement necessary for attracting multiple market segments seeking memorable travel experiences. In accordance, Tip [13], concurred that the long-term economic viability of the industry itself was at risk from destination degradation, beach erosion, deforestation, and population displacement. Therefore, the opportunity is significant for working with local communities to take advantage of market opportunities vis-à-vis developing sustainable tourism products. The challenge is to do so during a current downturn in United States (U.S.) tourism, which Kalwarski and Allen [14] stated that airlines and hotels were suffering the greatest damage.

It is common knowledge that human activities can impact global climate patterns, therefore the risks to the resources and the economy of Brevard County as well as the entire state of Florida, warrant an understanding and subsequent development of initiatives for addressing such concerns. Stanton and Ackerman [15] concurred that climate change has forever impacted the physical, economic, environmental, and social fabric of Florida communities. Currently, The Space Coast Climate Change Initiative (SCCCI) [16] works in conjunction with local governments to recommend strategic plans for addressing the unique concerns of Brevard County sustainability. These plans are reviewed on a regular basis in order to assure the efficiency and effectiveness of initiatives. The need for immediate concern is grounded in a study by Stanton and Ackerman [15], which concluded that the Space Coast is especially vulnerable to sea-level rise. Based on the study, it has therefore been determined that Brevard County ranks $1^{\text {st }}$ in terms miles of vulnerable major roads and railways; $4^{\text {th }}$ in terms of affected population; $5^{\text {th }}$ in total land submerged; and $8^{\text {th }}$ in the number of vulnerable housing units. Although investments have been made in the historic sections of Cocoa, Melbourne, and Titusville, these ventures have not been aligned with and into major tourist attractions which might serve as the catalyst for increasing global favour in Brevard County from tourists of diverse cultural backgrounds.

As NASA winds down the human space program, with shuttle launches ending in either late 2010 or early 2011, an "out of the box" thinking approach as 
is evident of other counties such as Broward, Dade, Orange, Volusia, etc., may be needed. For example, in Volusia Country, the idea of an annual motorcycle parade in which thousands of enthusiasts visit Daytona Beach and then disseminate throughout the state, is an effort which creates added revenue for the county. In addition, the National Association for Stock Car Auto Racing (NASCAR) has contributed to the image of Volusia County with the Daytona Speedway. The Daytona Speedway has become a national spectator sport, which implies that Brevard County may need to pull from the major tourism attractions, such as Disney and Universal Studios, and establish a unique niche from which to create excitement. The beaches, refuge and wilderness locations, which include the Brevard County Zoo, are easily reached throughout the county, yet large-scale fishing, including charter fishing, airboat rides, cruise ships, and nature tour boats, are not as prevalent as one might find in Southern Florida counties. As for Brevard County malls, there is a need for vendors that will trade currency for American dollars as is currently being provided by various malls in other counties. In addition, Brevard County does not have any brand name designer outlet shops as are found in the neighbouring Indian River, Orange, and Volusia counties. As such, the local international air and sea ports must showcase Brevard County as more than appearing to be a stop-over for outside of the county attractions. The endeavour will be great in as much as it must be grounded in sustainability for the feasibility to be actualized in terms of environmental, economic, physical and social growth and development. It has been stated that Brevard County is the best kept secret in the state of Florida. However, what is needed is a conservative effort of local, state and private corporations as well as private foundations and higher education involvement to create the desire in others to seek to experience all that Brevard County has - and all that it can offer in the future.

\section{Tourism life cycles}

According to Karplus and Krakover [17], only a limited number of tourism models describe the evolutionary process of tourism areas. The best known tourism life cycle model encompassing the stages of birth to maturity and decline has been augmented by Butler [18] to include the following stages which has developed into a cornerstone in tourism research development: 1) exploration; 2) involvement; 3) development; 4) consolidation; 5) stagnation and; 6) either decline or rejuvenation. Although Butler's model has been one of the most significant tourism research paradigms, it is important to note that tourism areas evolve based on unique internal and external factors including those which may be unknown or immeasurable which implies that it is practically impossible for one model to account for all variances in the tourism life cycle [17]. Measuring tourist aversion to sustainable practices may be difficult to measure - yet these practices greatly impact the success of a sustainable tourism initiative at all phases of a life cycle. Giannoni [19] conceded that visiting tourist generate overcrowding and waste, which means that in order to attain and increase sustainable growth, a location must develop mass-tourism 
based on environmentally friendly facilities. This may be a challenge according to the author [19] due to the large scale application and initiative toward tourist rejuvenation and potential increase in growth. Pollution for example, arises from additional sources in which the building of tourism facilities is seen a source of visual pollution for residents and destroys part of the natural habitat of the ecosystem [19]. As many industries are faced with an uncertain economic future, downsizing and restructuring, the opportunity for tourism as a catalyst for the movement toward a simpler life which is described by Tip [13] as placing family and interpersonal relationship above that of material possessions. Translated into travel, this can offer more meaningful experiences with local people and cultures, as opposed to spending a large portion of time in guided tours or allinclusive resort establishments. Local communities must therefore develop cooperative partnerships in order to work toward attaining shared goals [13]. Accordingly, an understanding of the tourism life cycle is an integral component of an all-encompassing effort toward strategic planning for sustainable successful tourism planning and initiatives.

\section{Tourism data sets}

To create an awareness of the importance of tourism for Brevard County, a study was compiled by the Brevard County Economic Impact Analysis of Tourism and presented by Price [20], which provided an analysis of tourism contribution to the local economy. A brief summary of the findings indicated that in 2008, tourists spent \$2.89 billion in Brevard County among which included the following monetary allocations: Lodging: $\$ 839,474,000$ million; Dining: \$509,809,000 million; Entertainment: \$120,437,000; Retail Purchases: $\$ 450,323,000$; Kennedy Space Center: $\$ 597,065,000$ and; Port Canaveral: $\$ 109,626,000$. The majority of Brevard County tourists are from the following ten states: Florida, Ohio, Illinois, Michigan, New York, Virginia, Wisconsin, Georgia, Minnesota and Pennsylvania. Global visitors are primarily from Canada, England, Germany, Italy and China [20].

Brevard County holds art festivals each spring or fall along with various annual festivals throughout the year. Statistics from the Brevard Cultural Alliance [21], illustrated the average cultural attendee spent $\$ 20.80$ per event, while $20 \%$ of cultural tourists spent an average of $\$ 38.17$ per event for 2008 . During 2007, the non-profit arts and culture industry contributed over $\$ 42$ million to Brevard County [21]. In addition, The Annual Grant Seafood Festival attracts approximately 50,000 people for the 2-day February event. Established in 1966, it is now the Southeast's largest and longest running seafood festival [22]. According to Prada [23] however, data suggested that Florida tourism will not recover until well after the national economy rebounds. Visits by nonFloridians have fallen by as much as $9 \%$ during the fiscal year ending June 3, 2009, according to the state legislature's Office of Economic and Demographic Research. Connor [24] stated that the average annual salary at Kennedy Space Center, which draws huge crowds for shuttle launch events, was $\$ 77,235$ or doubles that of the typical worker in Brevard County. As a result, if the shuttle 
program ends, this can have a negative effect on the local economy by affecting the gross each year. Best [25] concurred that the hotel and tourism industry will have its ups and downs in 2010. On the other hand, two major 4,000 plus passenger cruise ships are expected at Cape Canaveral Port: this will positively affect tourism growth for 2010 [25].

\section{The Space Coast Tourism Model (SCTM)}

The Space Coast Tourism Model (SCTM) is designed around existing modelling strategies $[2,4,5,10]$. However, the research design for the SCTM is non experimental and qualitative. Because of the qualitative nature of the research, the main tourism statistical measurements should be descriptive statistics for the demographic data and analysis [9, 11, 12]. The SCTM addresses questions on tourism planning initiatives to gauge tourism on the Space Coast of Brevard County, Florida. The SCTM uses 6 years of tourism life-cycle and data sets to answer questions on where and how people travel from various origins and combines these patterns with forecasts of visitor growth to estimate how the demand for travel is likely to change in the future. The SCTM flow includes traveller types, traveller origins, year and season, and transport modes. The origin-destination analysis is segmented by mode of transport - what mode of transport tourist use for travel destinations. The modelling completes the network flow analysis by converting travel demand to estimates of transport usage. In addition to travel decisions of where to go and how to get there, the model addresses what to do when tourist reach their destination [9, 10]. The activity parameters include visits, visitor nights, expenditure, accommodation type, transport type, activities undertaken, age group, and travel style. In addition, the SCTM presents flows that describe processes to define spatial layers, data sources, and how to manage data of sample sizes [2, 9]. Results reveal modelling, based on an origin-destination style, models and projects the movements of domestic and international tourists as a valid tool for providing past, present, and future estimates of tourism on the Space Coast. In conclusion, the Space Coast model presents flows of different types of tourist by road and air, forecast tourist flows over time, shows tourism intensity on the Space Coast, and tourist destination with purpose and activities $[1,9,10]$.

\section{Conclusions and recommendations}

This research effort was explanatory in nature and chooses a qualitative approach to give content description, interpretation, verification, and evaluation of tourism related activities for the Space Coast in Brevard County, Florida [7, 12]. The paper proposes a model as a valid tool for providing public agencies with accessible information to make important tourism related decisions for the Space Coast in Brevard County, Florida. We have proposed data analysis from complementing tourism life-cycle and data sets to extract information for a Space Coast Tourism Model to build a picture of current and future tourism flows in the county $[2,5]$. The SCTM provides answers to problems dealing 
with strategic planning initiatives for the county and is an analysis tool for tourism stakeholders to understand the impact of tourism growth and the development of sustainable and unsustainable tourism industries for the area. In addition, the model provides identification areas for private and public investments with for high impact revenue. The model will contribute towards strategic planning initiatives for the purpose of filling the void between anticipated NASA's workplace downsizing and the reduction of tourist activity on the Space Coast.

Tourism, according to Jackson [26], was often used as a national or regional development tool, which can positively or negatively impact the community, therefore policymakers must employ a model which minimizes the perceived negative impact of tourism planning. Brevard County has a very strong potential for attracting tourists from around the world. The emphasis should therefore be on a long-term plan in which monetary allocation can be made available both in the form of small business loans and grants for local business to develop "out of the box" events. The application of such events should be different from what is found in other Florida counties which depict the eco-system while becoming a mecca for convention themes encompassing areas such as education, health, industry, and technology. Brevard County additionally needs to adjust to the end of the shuttle space program and the reality that NASA may or may not remain with the Space Coast. With the proposed model in place, these events should not be considered to be major strategic disadvantages against the tourism economy of the county.

\section{References}

[1] Dinica, V., Governance for sustainable tourism: a comparison of international and Dutch visions. Journal of Sustainable Tourism, 17(5), pp. 583-603, 2009.

[2] Vuletich, S., Tourism Flows Model Methodology, prepared for Ministry of Tourism, October 2006, Covec: Auckland, New Zealand, 2006.

[3] May, M., Gunter, C., \& Lee, I., Privacy APIs: access control techniques to analyze and verify legal privacy policies," $19^{\text {th }}$ IEEE Workshop Security foundations, pp. 85-97, 2006.

[4] Giorgini, P., Massacci, F., Mylopoulos, J., \& Zannone, N., Modeling security requirements through ownership, permission and delegation, 12 IEEE International Conference on Requirements Engineering, pp. 167-176, 2005.

[5] Alvares, D. \& Lourenco, J. Life Cycle Modelling for Tourism Areas, unpublished Ph.D. thesis: Minho University, Portugal, 2007.

[6] Arthur, W. The Nature of Technology, Free Press: New York, New York, 2009.

[7] Leedy, P. \& Ormrod, J. Practical Research: Planning and Design, Prentice Hall, Upper Saddle River, NJ, 2004.

[8] Al-Fedaghi, S., Interpretation of information processing regulations. Journal of Softwater Engineering Applications, 2, pp. 67-76, 2009. 
[9] Blanchard, B. Logistics Engineering and Management, Prentice Hall: Upper Saddle River, New Jersey, 1998.

[10] McDonald, J., Complexity science: an alternative world view for understanding sustainable tourism development. Journal of Sustainable Tourism, 17(4), pp. 455-471, 2009.

[11] Sirakaya, E., McLellan, R., \& Muzaffer, U., Modelling vacation destination decisions: a behavioural approach. Tourism Analysis, 13, pp. 57-75, 2008.

[12] Bradberry, T. \& Greaves, J., The Emotional Intelligence Quick Book, Simon and Schuster, New York, New York, 2005.

[13] Tip, B.P., Sustainable tourism. International Trade Forum: Geneva, 1, 2123, 2009.

[14] Kalwarski, T. \& Allen, L.D., U. S. travel and tourism are going nowhere. Business Week, 4157 (17). Nov. 30, 2009.

[15] Stanton, E.A. \& Ackerman, F., Florida Climate Change: The Cost of Inaction, Tufts University, 2007.

[16] East Central Florida Climate Change Task Force \& RWP Parkinson Consulting, Inc. Background Goals \& Objectives and Sea-Level Rise. http://spacecoastclimatechange.com/mission.html. (2008).

[17] Karplus, Y. \& Krakover, S., Stochastic multivariate approach to modelling tourism area life cycles. Tourism and Hospitality Research, 5(3), 235-253, 2005.

[18] Butler, R.W., The concept of a tourist area cyclical evolution: implications for a management of resources. Canadian Geographer, 24(1), 5-12, 1980.

[19] Giannoni, S., Tourism, growth \& residents' welfare with pollution. Tourism \& Hospitality Research, 9(1), 50-61, 2009.

[20] Price, W. T., Tourist Dollar Dreams. Florida Today, 1E. April 19, 2009.

[21] Brevard County Cultural Alliance. Arts as Economic Stimulus: The Economics of Creativity. http://www.artsbrevard.org/docs/arts-aseconomic-stimulus.html. 2009.

[22] Grant Seafood Festival. Next Schedule. www.grantseafoodfestival.com /seafood-festival-history-aspx. 2009/2010.

[23] Prada, P. Recesssion Chills Sunshine State Tourism. Wall Street Journal, A3, August 15, 2009.

[24] Connor, M., Florida's space economy threatened by shuttle's end. Science News, 2009.

[25] Best, K. 2010 Business Outlook. Florida Today, E1, December 27, 2009.

[26] Jackson, L.A., Residents' perceptions of the impact of special event tourism. Journal of Place Management \& Development, 1(3), 240, 2008. 